\title{
CONSPECTVS HVIVS FASCICVLI
}

\begin{tabular}{|c|c|c|}
\hline Praefatio & CXXVII & \\
\hline 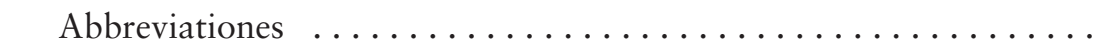 & CXXXI & \\
\hline Conspectus auctorum operumque laudatorum $\ldots \ldots \ldots \ldots \ldots$ & CXXXIII & \\
\hline Periodica seriesque abbreviate laudatae & CLXXIII & \\
\hline 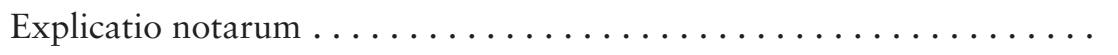 & CLXXIX & \\
\hline Pars tertia: Marrucini $\ldots \ldots \ldots \ldots \ldots \ldots$ & $1267-1305$ & $6974-7039$ \\
\hline LXVI. Teate Marrucinorum & $1267-1305$ & \\
\hline Addenda et corrigenda $\ldots \ldots \ldots \ldots \ldots \ldots$ & $1267-1275$ & $\begin{array}{r}321 *-326^{*} . \\
3012-3042.6316-6318\end{array}$ \\
\hline Falsum & 1275 & $777 *$ \\
\hline 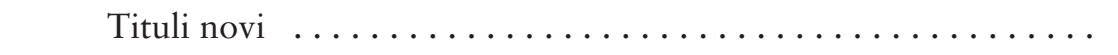 & $1275-1305$ & $6974-7039$ \\
\hline Pars quarta: Paeligni . & $1306-1545$ & $7040-7446$ \\
\hline LXVII. Pagus Interpromium & $1306-1331$ & \\
\hline Addenda et corrigenda $\ldots \ldots \ldots$. & $1306-1312$ & $\begin{array}{l}326^{*} \cdot 337^{*} \\
3043-3073\end{array}$ \\
\hline Tituli novi & $1312-1331$ & $7040-7099$ \\
\hline LXVIII. Sulmo . . . . . . . . . & $1332-1400$ & \\
\hline Addenda et corrigenda $\ldots \ldots \ldots \ldots$ & $1332-1345$ & $\begin{array}{r}329 *-331 * .339 * .766 * \\
3074-3136.3227 a .6319-6321 . \\
6408 a\end{array}$ \\
\hline Falsae vel alienae & 1345 & $778 *-780 *$ \\
\hline 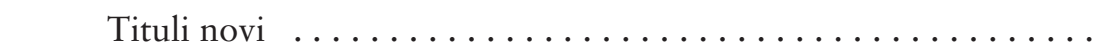 & $1346-1400$ & $7100-7220$ \\
\hline LXIX. Pagus Lavernae $\ldots \ldots \ldots \ldots \ldots \ldots \ldots \ldots \ldots$ & $1400-1404$ & \\
\hline Addenda et corrigenda $\ldots \ldots \ldots \ldots \ldots \ldots \ldots \ldots$ & $1400-1402$ & $\begin{array}{r}335^{*} \\
3137-3143\end{array}$ \\
\hline Tituli novi & $1402-1404$ & $7221-7225$ \\
\hline 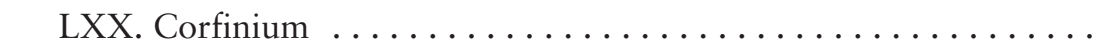 & $1405-1508$ & \\
\hline Addenda et corrigenda $\ldots \ldots \ldots \ldots \ldots \ldots \ldots \ldots$ & $1405-1442$ & $\begin{array}{r}327 *-328 * .332 \% \cdot 334 * \cdot 338 * \\
\text { p. } 298 \text { a-g. } 3121 \text { a. } 3144-3301 . \\
\text { p. } 678 \text { (ad p. 297). p. 679 h-q. } \\
\quad 6322-6346.6408 \mathrm{~b}-6412 \mathrm{a}\end{array}$ \\
\hline Tituli novi & $1442-1508$ & $7226-7381$ \\
\hline LXXI. Superaequum & $1508-1545$ & \\
\hline Addenda et corrigenda $\ldots \ldots \ldots \ldots$ & $1508-1519$ & $3181.3245 .3302-3335$ \\
\hline 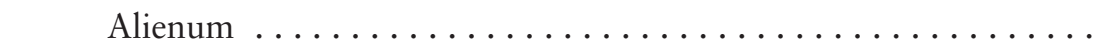 & 1520 & $781 *$ \\
\hline 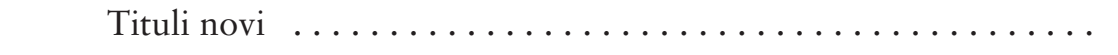 & $1520-1545$ & $7382-7446$ \\
\hline Pars quinta: Vestini & $1546-1693$ & $7447-7638$ \\
\hline LXXII. Aternum vicus $\ldots \ldots \ldots \ldots \ldots$ & $1546-1549$ & \\
\hline Addenda et corrigenda $\ldots \ldots \ldots \ldots \ldots \ldots \ldots \ldots \ldots \ldots \ldots \ldots \ldots \ldots \ldots \ldots$ & $1546-1548$ & $\begin{array}{l}341 *-347 * \\
3336-3341\end{array}$ \\
\hline Tituli novi & $1548-1549$ & $7447-7448$ \\
\hline LXXIII. Angulus $\ldots \ldots \ldots \ldots \ldots \ldots$ & $1549-1550$ & \\
\hline 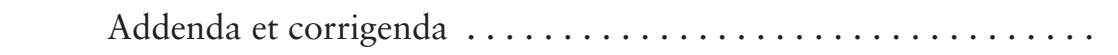 & $1549-1550$ & $3342-3346$ \\
\hline
\end{tabular}




\begin{tabular}{|c|c|c|}
\hline CONSPECTVS HVIVS FASCICVLI & CXXVI & CIL IX \\
\hline & p. & n. \\
\hline LXXIV. Pinna Vestina & $\ldots \ldots \ldots 1551-1575$ & \\
\hline Addenda et corrigenda ... & $\ldots \ldots \ldots 1551-1556$ & $\begin{array}{r}348 * \\
3347-3374\end{array}$ \\
\hline Tituli novi $\ldots .$. & $\ldots \ldots \ldots 1556-1575$ & $7451-7493$ \\
\hline LXXV. Aufinum ......... & $\ldots \ldots \ldots 1575-1593$ & \\
\hline Addenda et corrigenda $\ldots \ldots \ldots$. & $\ldots \ldots \ldots \ldots 1575-1583$ & $3375-3413$ \\
\hline Falsum $\ldots \ldots \ldots \ldots \ldots \ldots$ & $\ldots \ldots \ldots \ldots$ & $782 *$ \\
\hline Tituli novi $\ldots \ldots \ldots \ldots \ldots \ldots$ & $\ldots \ldots \ldots \ldots 1584-1593$ & $7494-7519$ \\
\hline LXXVI. Peltuinum Vestinum ........ & $\ldots \ldots \ldots \ldots \ldots 1593-1643$ & \\
\hline Addenda et corrigenda $\ldots \ldots \ldots \ldots$ & $\ldots \ldots \ldots 1593-1617$ & $\begin{array}{r}352 \% \\
3323.3414-3512.4209\end{array}$ \\
\hline Tituli novi & $\ldots \ldots \ldots 1617-1643$ & $7520-7596$ \\
\hline LXXVII. Furfo $\ldots \ldots \ldots \ldots \ldots \ldots$ & $\ldots \ldots \ldots \ldots \ldots$ 1644-1660 & \\
\hline Addenda et corrigenda $\ldots \ldots \ldots \ldots$ & $\ldots \ldots \ldots \ldots 1644-1656$ & $\begin{array}{r}349^{*} \\
3513-3568\end{array}$ \\
\hline Tituli novi & $\ldots \ldots \ldots 1656-1660$ & $7596 a-7604$ \\
\hline LXXVIII. Vicus potius quam Pagus Fificu & $\ldots \ldots \ldots \ldots 1661-1675$ & \\
\hline Addenda et corrigenda $\ldots \ldots \ldots \ldots$ & $\ldots \ldots \ldots \ldots \ldots$ 1661-1668 & $\begin{array}{r}351^{*} \\
3569-3601\end{array}$ \\
\hline Tituli novi & $\ldots \ldots 1668-1675$ & $7605-7621$ \\
\hline LXXIX. Aveia Vestina ............. & $\ldots \ldots \ldots \ldots \ldots 1675-1693$ & \\
\hline Addenda et corrigenda $\ldots \ldots \ldots \ldots$ & $\ldots \ldots \ldots \ldots \ldots 1675-1685$ & $\begin{array}{r}353 * .767 * \\
3602-3648.4194\end{array}$ \\
\hline Tituli novi $\ldots \ldots \ldots \ldots$ & $\ldots \ldots 1685-1693$ & $7622-7638$ \\
\hline $\begin{array}{l}\text { Index minor } \ldots \ldots \ldots \ldots \\
\text { Tabellae synopticae } \ldots \ldots\end{array}$ & 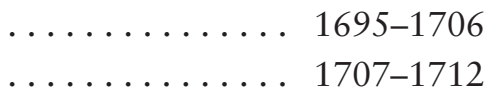 & \\
\hline
\end{tabular}

